Dance Performance and Virtual Reality - an investigation of current practice and a suggested tool for analysis. 


\section{Dance Performance and Virtual Reality - an investigation of current practice and a suggested tool for analysis.}

\section{Introduction}

This article is a contextualisation of recent dance practice made for/in Virtual Reality (VR) and a discussion of any characteristics of that work. For the purpose of this article, my definition of VR includes both 360 film experienced through a VR headset, as well as computer generated virtual environments, also experienced through a VR headset. This article will forefront practice, and whilst drawing on relevant theories and frameworks, will avoid becoming preoccupied with wider issues such as notions of performativity in in VR, or questions around the digital body for example.

Across the 1990s and early 2000s much was written about the potential of Virtual Reality within performance (Brenda Laurel, 1991, Howard Rheingold, 1991, 1994, Scott deLahunta, 2004, Gabriella Giannachi, 2004, Steve Dixon, 2006, 2007 and Matthew Causey, 2009), but as little performance work was being made, much of this writing was restricted to discussing and suggesting the future possibilities of the medium. In 1991 for example, Howard Rheingold summarised the ontology of Virtual Reality as three interdependent elements;

One is immersion, being surrounded by a three dimensional world; another one is the a ability to walk around in that world, choose your own point of view; and the third axis is manipulation, being able to reach and manipulate it. (Rheingold 1991, 34).

For contemporary practitioners, these 3 elements are not regarded as interdependent - many 360 films created to be experienced through VR headsets cannot be manipulated by the audience, for example. For this reason I am not going to attempt to align contemporary practice with these earlier ideas, but instead articulate what types of work experiments with VR dance has led to in practice. Where possible, I have included the exact words of the artists discussed rather than paraphrasing, 
in an attempt to keep the ideas of the artist at the forefront of the article. In my discussions, I am going to refer to 'audience' rather than 'viewer' as I am framing these pieces as dance works within an VR environment rather than dance on film (where I might have referred to 'viewers').

Following this introduction there will be a discussion about the relationship between performance and virtual reality, then a description of each of the 6 key works that this article will focus on, all of which premiered in 2016-7. The article will go on to analyse the work and outline key characteristics, including types of creative content and the role of the audience, as well as reflecting on the importance of interdisciplinary creative teams and collaborative partnerships. In addition, the article will present a tool for analysing and understanding VR dance performance work.

The relationship between performance and VR technologies has been ongoing since the initial development of VR in the 1980s. In 2006, Dixon reflected that the use of VR within performance contexts was 'highly under-developed' (2006, 23). In his 2002 journal article 'Virtual Reality and Performance', Scott deLahunta describes an 'absence of choreographers in virtual reality' (2002, 111), and questions 'why choreographers, so often on the forefront of experimentations with interactive technologies, seem at present much less involved in making a response to these environments?' (111) He continues to describe how, from the mid-1970s, choreographers demonstrated 'a clear preference for the coherence of conventional stage space/time' and although since the 1980s choreographers have explored a variety of interactive computer systems, this has not led to a more participatory practice, where the 'audience/viewer/user' can cross between the performance and spectating space. Rather, choreographers have integrated these technologies into more traditional theatre-based performances (111).

The last 15 years have witnessed a digital revolution that has seen digital technologies become an integral part of society, and as an integral part of the artistic practices within that society. Today, digital technologies are interwoven into many aspects of our daily lives and for many creative 
practitioners engaging with these technologies in their work is a natural fit. Digital technologies are now ubiquitous and pervasive, Matt Adams, from the artists' group Blast Theory remarking that 'the digital' is now so embedded in performance practice that is has become invisible (in Blake 2014, viii).

NESTA's report 'Beyond Live: Digital Innovation in the Performing Arts' (2010) describes a 'digital revolution' where digital technologies have led to 'seismic change' in both the expectation and behaviour of consumers. The report asserts that it is imperative for the UK's creative industries to rethink their relationship with consumers during this period of increased experimentation, exploring a wide range of platforms and strategies to reach audiences. Though the report refers mostly to technologies such as the internet and digital cinema it asserts that the act of translating cultural content to digital platforms may actually drive the development of art-forms themselves, creating new forms of experiences for audiences. As Carver and Beardon assert, for theatre 'to continue to act as a mirror to society it must engage with the changing means of communication which new technologies have brought about...' $(2002,152)$.

\section{Virtual Reality and Performance}

In Virtual Theatres, Gabriella Giannachi describes how the omnipresence of the internet has meant that it is no longer possible to engage in critical discourse about the 'real' without engaging with the virtual, reflecting how '...the virtual has become the main theatre of the real - the place from where the real can be viewed, a space for critique, art and politics' $(2004,124)$. Many other authors have also drawn similarities between theatre and the virtual space. Virtual Reality theatre designer Mark Reaney who descries theatre as 'the original virtual reality machine', enabling audiences to experience 'imaginary worlds which are interactive and immersive' (1996, 28). Steve Dixon (2007) writes how; 'Theater is always - already a simulation; it stands for something outside of itself. Theater is the inauthentic masquerading as the authentic; the unreal posited as the real. This basic paradigm is 
the same as in virtual systems... ' (p.153). For choreographer and technologist Yacov Sharir, digital systems create a new space, necessitating new behaviours; 'We still look at computers and video cameras as tools to do things with. I think I like to look at it as a world, a space. That once you participate in it, you find yourself new ways to behave in it... I like to think this as a theater space, as a performance space.' (1997) In Computer as Theatre (1991) Brenda Laurel asserts;

Computers are theater. Interactive technology, like drama, provides as platform for representing coherent realities in which agents perform actions with cognitive, emotional and productive qualities... Two thousand years of dramatic theory and practice have been devoted to an end which is remarkably similar to that of the fledgling discipline of human-computer interaction design; namely, creating artificial realities in which the potential for action is cognitively, emotionally, and aesthetically enhanced.

As Dixon reflects, VR offers 'an ideal technological medium with which to enhance fundamental elements core to the theatrical experience: visual spectacle, imaginary worlds and transformative spaces, and most significantly of all, audience immersion' $(2006,23)$.

In some ways dance performance is an ideal medium for VR. Many of the challenges faced by VR content creators, including how best to communicate narrative in a 360 space and how to direct the attention of the audience, are already being dealt with within live choreographic practice. Choreographer Gideon Obarzanek, describes how VR actually intensifies the connection between audience and dancer that is so central to live dance performances;

...it is even closer than live performance because you are actually in it and people are whizzing past you or hurdling towards you and moving away. One of the things I enjoy the most about watching dance in the real world is being in the dance studio and being really close. You know, you're not in a theatre, you are actually in a room with them and VR is a way of getting very close to dance. It's like being in the rehearsal room for dancers. (in Brooke Boland, 2017)

Lily Baldwin, choreographer of VR dance work Through You, describes how a 'greater sense of body' is possible when watching a moving body in VR, describing how 'It reincarnates the real life 
electricity of a performance - this outmoded art pastime that is getting lost in the digital world' (in DJ Pangburn, 2016).

VR enables practitioners to translate the multidimensional experience of live performance into the virtual space, and in a similar way to live performance, allows the viewer to choose where to direct their attention. Baldwin and Unseld describe how within VR, narrative becomes 'a conversation with the audience about interest and attention in a kind of mutual dance'. (in Randy Astle, 2017). Google Experience Engineer Elly Nattinger reflects how the expertise of performing arts directors in controlling the audience's focus provides them with the necessarily skills for developing work in VR, and suggests that these techniques should be studied and used by all disciplines working in VR (in Carla Escoda, 2017)

Arts commentator Jana Perkovic (2016) reflects how within VR, attention can be guided by lighting cues, directional sound and movement guiding the viewers attention, all techniques already inherent within choreographic practice. In addition, Paul Galando (2017), Programme Leader of the Virtual Reality Dance Programme at New York University, describes how dancers 'think volumetrically' and how this preoccupation with space gives an advantage when developing VR work. Galando asserts that VR seek out collaborations with choreographers and dancers because of their understanding of space and how to engage audiences through using that space.

\section{Recent VR dance works}

Over the last few years there has been an increase in the creation of dance work for VR environments, with a number of new pieces premiering in 2016-17. These works have been created across different countries and dance genres, by both established national dance companies and independent artists. For this article I have selected 6 works to discuss, Stuck in the Middle (Sydney Dance Company) Nightfall (Dutch National Ballet), Giselle (English National Ballet), Through You (Baldwin 
and Unseld), Dust (Boleslavský and Júdová) and Whist (AoI), which will provide 6 initial case studies through which to gain and overview of current practice. Unfortunately, the scope of the paper does not allow for a fuller and more detailed discussion about specific works, which will form the basis of future publications.

\section{Stuck in the Middle}

Stuck in the Middle (2016) was the first VR work commissioned by the Australian Centre for the Moving Image (ACMI) and is a collaboration between the ACMI, Sydney Dance Company, Jumpgate VR and Closer Productions, jointly created by director/choreographer Gideon Obarzanek and filmmaker Matthew Bate. Through the eight-minute piece, the viewer becomes part of an onstage performance by the Sydney Dance Company, Bate remarking;

I liked the idea that for the first time ever, Sydney Dance Company could dance for you and you alone - that their focus would not be an audience in the stalls, but rather the audience would be you, standing amongst them on stage' (ACMI 2017)

The piece begins with the viewer placed seated in the stalls of the theatre and then is transported on stage with the company during a performance. As the dance continues, the dancers approach the audience in the middle of the stage and directly address the audience (Perkovic, 2017) and finally, the viewer has the opportunity to becomes part of the performance themselves, as the dancers offer to teach them sections of the choreography. Stuck in the Middle is adapted from an earlier piece, L'Chaim (2014), choreographed by Obarzanek for the Sydney Dance Company, which Bale felt had potential for a VR re-working;

The original dance piece used this great conceit of a voice of God that interrupts the performance to ask questions of the dancers. We had this idea that the VR camera could be put on stage and become this interloper - and that the dancers could talk to and respond to this character that has crashed their dance performance. (NSW Government, 2018) 
Stuck in the Middle With You was shot using 12 Go-Pro cameras, stitched together in post-production to create a spherical 360 degree image. The piece consists of three shots, the first two in the auditorium and the final shot being one full take of the performance. At the ACMI showings of the piece, three participants wearing Oculus Rift headsets stood on a stage in-front of a seated audience. The three participants experienced the VR piece, which was simultaneously played on a large screen behind them, the audience able to see the participant experiencing the piece and the piece itself.

\section{Nightfall}

Nightfall (2016) is a coproduction between the Dutch National Ballet, Samhoud Media and Samsung and was described by the Dutch press as 'a key moment in dance history' (Samhoud Media, 2018). Choreographed by Peter Leung, the 8-minute piece is inspired by the 'white acts' form ballets such as Swan Lake and Les Sylphides. The website of the production studio describes the premise of of two lovers, trapped and enchanted by a violinist. For the Dutch National Ballet, Nightfall was an attempt to create a piece where the dancers seem to interact with the audience, in reaction to VR films that the company had experienced by the New York Philharmonic which they felt largely ignored the audience. Harm-Jan Keizer, the Dutch National Ballet's marketing manager reflected that as an audience member he had felt dislocated both from the work and those performing the work remarking, 'You felt like you were a ghost in a place where you didn't really belong. Nobody was looking at you.' (Sarah Bellman, 2017) In Nightfall, the audience is placed in the middle of a warehouse where the action takes place and is surrounded by the dancers. For the Director, this offers the audience a more intimate experience, enabling the audience to stand in the middle of the stage amongst the dancers, giving the impression of a personal performance (Dansmagazine, 2018). 
The piece was choreographed specifically for the virtual reality film, Leung describing how the piece took the viewpoint of the audience (Dutch National Ballet, 2016). For Leung, breaking new ground in the creation of a VR ballet was a challenging experimental experience, necessitating different approaches and problem solving, for example working with consideration of the camera's sightlines. Harm-Jan Keizer, Marketing Manager for The Dutch National Ballet recognised that the new environment offered by virtual reality required a kind of work different to that that they would make for the traditional stage environment;

As a dancer, you have one focus point, and that's the audience. But if you're working for virtual reality, then depending on where you are in the room, you have to change your direction. The choreography should really be different. So we realised we had to make something new. A new ballet. (in Sarah Bellman, 2017)

In 2016 Nightfall won the public choice award at the Bright VR Awards and in 2017 won the title 'best live experience' at the Cinequest Film and VR Festival.

\section{Giselle VR}

Giselle VR (2016) was created in partnership between the English National Ballet and Sky and was produced by the immersive content company Factory 42. The 2-minute piece is inspired by Akram Khan's live ballet Giselle and features Khan's choreography, Director Dan Smith reflecting how they wanted to enhance rather than change Akram Khan's Giselle (Sky Arts, 2016). The film is a solo female performance based in an industrial factory setting, filmed in 360 and embellished with VFX in the form of light trails to highlight the perfomer's moves without altering any of the choreography. (Sky Arts, 2016). For Khan, VR presents and exciting opportunity for new discoveries;

I think VR is unchartered territory. And in a sense the possibilities are immense. Your awareness is heightened because suddenly the reality is what you're seeing all around you, and there isn't some thing in between - there isn't space in-between, so you look down and you're on the ground where this film in taking place - it's surreal (Sky Arts, 2016). 
The filming took place over a short one-day time frame, the team working towards one two-minute take (Sky Arts, 2016). Giselle VR was one of the first pieces available on Sky's new virtual reality app, launched in October 2016.

\section{Through You}

Through You (2017) was created through a collaboration between director/choreographer/filmmaker Lily Baldwin and director and co-founder of Oculus Story Studio Saschka Unseld, supported through a Sundance Institute New Frontier Jaunt VR Residency. Their first formal venture into dance in a virtual space, the 14-minute piece explores themes of intimacy and mortality and features the evolving relationship of a couple over decades, from youth to old age. The artists explain how at the beginning of the piece the audience are in the role of Julia's lover but then, after she walks through the audience and leaves, they see Julia's life continue without them (in Pangburn);

The presence we embody in the experience is the memory of our main dancer has of a lover in her youth... We, the presence of her memory, stay with her throughout her whole life. We are her unre lenting memory (never-ending connection, enduring witness). We exist through her. We are her ca pacity to love and feel... (ibid).

Like a traditional film set, each scene was designed with production elements specific to each decade. However, unlike a traditional film, Through You does not follow a traditional narrative, but instead is 'a series of 'peak moments of being' that were strung in a bold tableau'. For Baldwin, the aim was to create a work that was bound with the affordances of VR - that couldn't exist in any other medium and would not be possible in real life. (Baldwin, 2016) She continues;

We both wrestle with linearity. Real life happens in simultaneous layers, which is how we experience time and therefore story. Creating in 360 degree space was a relief, and has left us thinking of story in terms of 'slices of life'... I think of it as walking through a museum and stepping inside a series of paintings (each one a complete world) on the wall... Time plays differently because there's so much to see! Because you're intimate with the environment, little things become epic. (ibid) 
Through You was created through the kind of experimental iterative process often practiced in devised performance rather than a traditional scripted filmmaking approach;

We decided pretty early on to shoot long takes of experimentation for each narrative moment in our protagonist's life. We ran multiple improvisational takes of over ten minutes of length that in the end might just be one minute of narrative. What we found early on was that the key here was not to prescript everything to the second, something that is, if we're honest, impossible if we truly ascribe to the idea that it's a medium with not yet written rules. Instead we found the flow of each time fractures (as we called each edit) as it relates to movement and narrative in edit (Unseld and Baldwin, in Astel).

Baldwin describes how they only really established what had worked during post production, through a lot of trial and error (Pangburn). This experimental approach extended to both the filming and editing techniques, Baldwin and Unseld rejecting many of the so-called 'established' rules of VR filmmaking. In 360 filming, the camera is usually static so that the audience is stationary, with the movement happening around them, to avoid any motion sickness that may be triggered by sudden or sustained movement (Pangburn). However, in Through You, Baldwin describes how they used 'a breathing handheld camera' (Baldwin in Pangburn), which enabled a duet between dancers and camera;

On set we were there, with our dancers, in the space. Moving the camera was about feeling what the right spatial relationship to the dancers was, in relation to their movement, their energy and the space in general. It's about feeling the energy there is in the room and going with that flow. Or, if some thing aggressive is needed, taking over that flow and pushing against it.

This approach usually leads to much lengthier and costlier processes - as the camera is moving, it is visible in every shot and must be painted out during post production. However, Baldwin and Unseld avoided this problem by dressing in black and performing on a black floor which meant they were invisible against the ground (Pangburn). The piece also exhibits experimental approaches to editing VR work. Traditionally, VR pieces are slow with few cuts which can cause confusion in the audience. In Through You however, the creators developed what they regard as a more radical ap- 
proach, cutting with speed and rhythm in an attempt to emulate a stream of consciousness (Pangburn). Through You was released on Samsung Gear VR via the Occulus Video app.

\section{Dust}

Dust (2017) is a collaboration between digital artists Andrej Boleslavský and Mária Júdová and choreographer Patricia Okenwa, produced by Carmen Salas with the support of the Arts Council of England and Slovak Arts Council. The 4-minute piece was inspired by Eugene Thacker's book In the Dust of this Planet, which explores the idea that everything is formed from stardust. The artists described how they were interested in exploring the experience of becoming a dust particle, and the ways in which it may change perceptions of body, space and time (Kevin Holmes, 2017). The audience are placed in the immediate virtual presence of the dancer, becoming dust particles and are able to float around freely, even stepping inside the dancers, gaining unique perspectives in terms of both concept and viewing points. (Boleslavský 2017). The audience are able to see their effected hands and feet within the virtual environment;

We've created a parallel universe with its own physical laws governing space. A world, in which you experience how your physical body disintegrates into millions of particles and you fly around freely and unnoticed. Perhaps a world, which makes you imaging how it would be to see the world from a different perspective. (Boleslavský and Júdová, in Holmes)

Dust was created using custom software tools that enabled the capture, edit and preview of volumetric recordings of dancers in VR (Sedor, 2017). The artists used Kinect cameras to emerge real and virtual worlds, streaming volumetric imagery into VR and combining it with dance recordings and photogrammetric environments in real-time. The audience and rendered elements share the same space and interact within that space, creating the impression that the audience is in the immediate presence of the dancer and within the space where the dance is happening (ibid.) 
In the filmed trailer for Dust, the audience stand, wearing HTC Vive headsets. Each has an individual experience, which was simultaneously played on a large screen near them, enabling non-participating audience members to see both the participant experiencing the piece and the piece itself.

\section{Whist}

Whist (2017) was created by the UK-based dance company AoE in collaboration with the creative production house Happy Finish, and co-produced with the Gulbenkian Canterbury and Tanzhaus Dusseldorf. The company describe the piece as blending art installation, 360 interactive film and physical theatre to experiment with a new form of storytelling inspired by Virtual Reality technologies (Esteban Fourmi, JiaXuan Hon and Aoi Nakamura 2016, 195). Inspired by Freud's case studies, the piece explores unconsciousness both though the multiple narratives and the audiences own decision making process (ibid). In making Whist, AoI had 2 main aims - firstly to make the audience's decision making invisible, and secondly, to enable audience to experience dance theatre in a new environment, unrestricted by reality (196). In doing so, the company hoped to make a performance where the audience member is at the heart of the show, and is able to influence their own experience (Lee, 2018).

The audience enters a room full of large sculptures and put on a Virtual Reality headset. There is a live feed into the VR headset, and by looking at the sculptures, the audience trigger virtual experiences. Each sculpture takes the audience member to a different room within the performance and from there are 76 possible virtual journeys through the experience, associative non-sequential scenes drawn from Freud's The Interpretation of Dreams. The journey of each audience member is directed through gaze-based navigation - where they are focussing on in each film will influence which film they see next. The experience culminates with a download code tor receive an online psychological analysis based on the element you showed an interest in. The audience is able to explore both the physical and virtual world they are in and instead of being a passive observer, 
has an active role in the unfolding story (Rebecca Hills-Duty, 2017a). The ways that the audiences engaged with the piece differed across performances. Rebecca Gordon reflected how whilst some audience members sat quietly, others laughed at the scenarios - the audience naturally took ownership of how they want to engage with the piece (2017).

The piece took two years to develop and AoI followed a traditional filmmaking process - firstly writing the script and creating the storyboard, then casting and finding locations and finally creating the film set and shooting the film. To this traditional filmmaking process was added what the creators refer to as the 'three-dimensionality of immersive theatre making, including depth and height in the storyboard, audience movement in the script and locations that could be experienced in 360 (Fourmi et al p196). Decisions on camera movement were made based on artistic merit as much as on considerations relating to VR motion sickness (ibid). James Brown from Happy Finish describes the technical process as complex and challenging, involving multiple rigging challenges, head mounted shots and ceiling suspension (Little Black Book Editorial).

\section{Discussion of Current Practice}

What is evident from the descriptions of the work listed above is the diversity of practice. Some of the pieces are performances filmed in 360 , others are within computer generated environments. Some of the pieces are adaptations of existing work, others are newly devised. Some of the pieces are filmed in one shot, others are a collection of scenes. Some of the pieces involve many performers, one is a solo. Some of the pieces were made with the aim to engage new audiences, where others hoped to create a new artistic language. Rather than focus on the difference between these works however, I propose to draw out a number of characteristics of this VR dance performance work, namely Types of Work and Audience Role, Collaborative Partnerships and the Development of New Languages and New Audiences. 


\section{Types of Work and Audience Role}

To begin to categorise this work, I have used the 15 categories of content types devised by Limina Immersive in their report for Digital Catapult (2018). Three of the 15 categories relate to the works discussed in this paper - Up Close and Personal (Stuck in the Middle, Whist), Activity Simulator (Dust) and Short Fiction (Giselle, Nightfall). All six of the pieces discussed in this article use the affordances of the VR environment to offer a more active role for the audience. For the purpose of this discussion I have categorised these as Active (the audience being asked to take an active role in tracking the performance around the 360 space), Participatory (the audience being asked to participate in the performance) and Interactive (the audience being asked to change elements of the work through interacting with the piece). These categories each build on the other - all the pieces discussed ask the audience to take an active role, some ask the audience to take and active and participatory role and a couple ask the audience to take active, participatory and interactive roles within the work.

All six pieces require the audience to take an active role, through tracking the performances around the 360 space. Peter Lueng, choreographer of Nightfall hoping that '...the fact that they [the audience] can look around, and have some choice in what they look at will make it a unique experience'. (Dutch National Ballet) In Stuck in the Middle, Dust and Whist, the audience is also required to participate in the performance, rather than solely experiencing the piece. In these 3 pieces audience members are a key part of the piece, either as acknowledged characters within the experience (Stuck in the Middle and Whist) or as part of the mechanics of the piece (Dust). Stuck in the Middle inverts the more traditional audience-performer perspective, acknowledging the viewers presence, and inviting them to participate in the experience. For Bale, much VR work he had experienced prior to 2016 positioned the viewer as a passive viewer, an unacknowledged presence and in contrast to this, the piece recognises the existence of the audience member as a human presence 
amongst other people (Boland 2016), commenting, 'You are the character. You are the actor on stage.' (Sydney Dance Company) At the end of the piece, dancers on the film invite the viewer to join the performance and offer to teach the viewer a dance. In Dust and Whist, the audience are able to interact with the pieces. In Dust, the audience see their bodies in the same virtual space as the dancer and as dust particles, are able to float around freely, even stepping inside the dancers and placing the audience member in the same occupied by the dancer, with the aim of forging an emotional connection between dancer and audience (Hills-Duty 2017b). In Whist, the narrative is decided by gaze-based navigation - where the audience focus during each section of film influences the section of film that they are shown next. Artistic Directors Esteban Fourmi and Aoi Nakamura describe how they are interested in how VR can extend the bodily, visceral experience of the dancer to audience members (2016).

Whilst these different pieces enable audiences to take a more active role, audience interactive agency is still limited, either to choices of what to watch (Nightfall, Giselle, Through You), inclusion in the virtual environment (Dust), joining in with dance movement (Stuck on You), or unconsciously selecting the next scene (Whist). The pieces discussed for example, do not allow the audience to interact with performers in real time on an individual level, for example through live streaming into VR, and as such audiences are unable to have direct agency on events.

\section{A Tool for Understanding VR dance work}

To get a clearer understanding of the Types of Work and Audience Role inherent in the works discussed I have created a table within which to place the different pieces, relating to environment, content and audience role (fig 1.) The horizontal axis relates to the type of virtual environment experienced by the audience, using the trajectory presented by Limina Immersive, from the represen- 
tation of an environment (for example filmed 360 footage) through to the simulation of experience (for example through computer generated visuals). The vertical axis relates to the role of the audience, segmented into the 3 types discussed earlier in this paper; active, participatory and interactive. The colour-coding of each work relates to the category of content within which the piece sits, as characterised by Limina Immersive, Short Fiction, Up Close and Personal and Activity Simulator. By placing each work within these axis, we can gain a greater understanding about the different works.

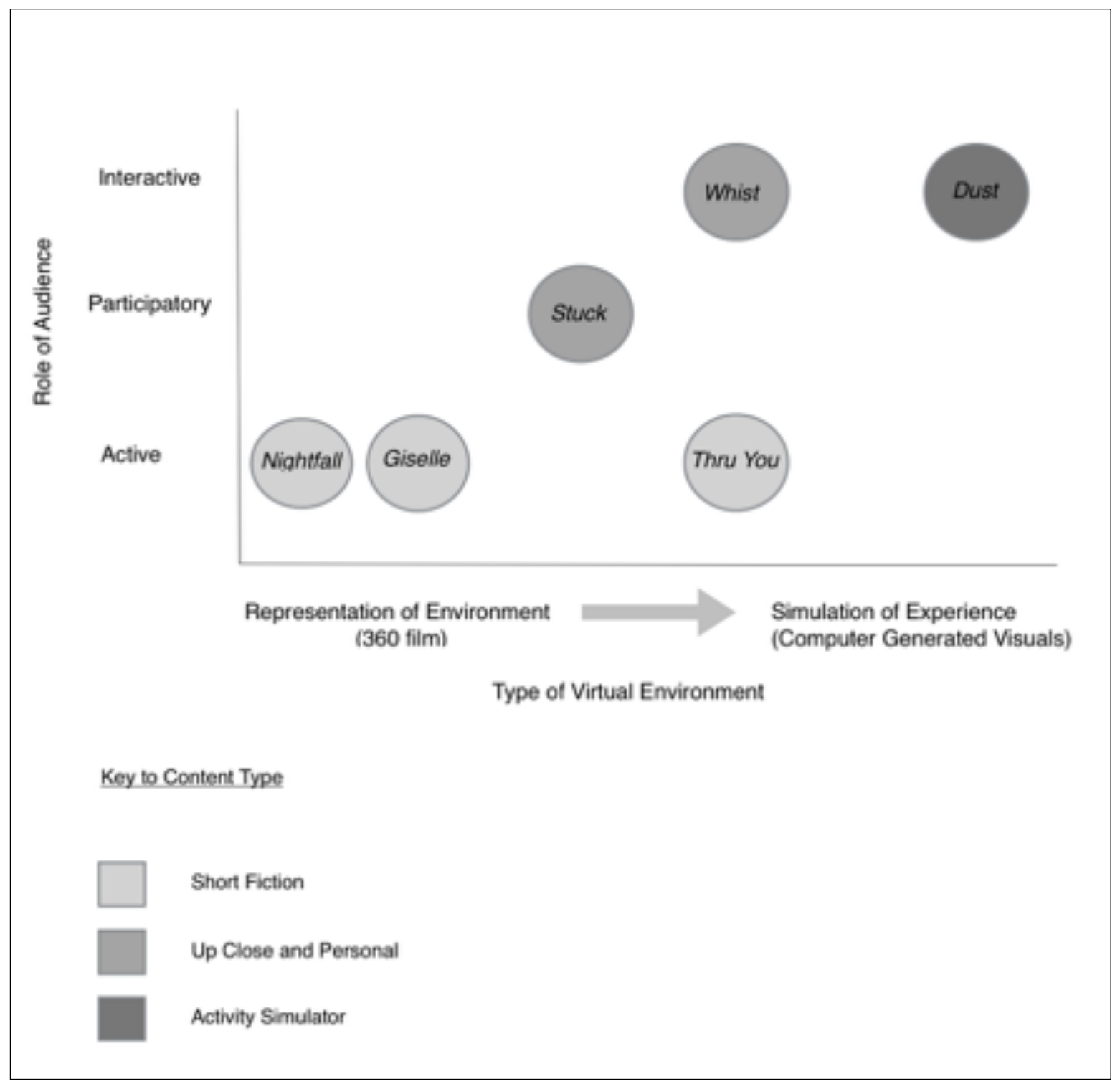

Figure 1. A Tool for Understanding VR dance work - environment, audience and content type. 
Nightfall, as a 360 film within a studio theatre environment is placed the furthest to the left. Audiences are able to visually navigate the 360 space utilised during the performance. Giselle is similarly an active 360 filmed experience, though is placed further along the environment trajectory as the performance is away from the traditional performance environment, situated within a disused factory building. Stuck in the Middle is a filmed 360 experience, but unlike the others that remain in one environment, the location of the film changes during the performance, as the audience member moves from the theatre auditorium to onto the stage. Whist and Through You are aligned in terms of environment, though the type of content differs. Both pieces are filmed in 360 , but the narrative of both is constructed around a number of different scenes in different environments (both domestic interiors). However, whilst Through You offers the audience member an active experience through being able to navigate space visually, Whist requires the audience to interact with the piece via gaze-based navigation. Dust is the one piece categorised as an 'Activity Simulator' in terms of content, the audience directly interacting with the virtual performance, becoming part of the computergenerated imagery. What is apparent is that dance works of all types of content are able to move within the trajectories of environment and audience role. Across the spectrum of environment, the type of content (Short Fiction, Up Close and Personal or Activity Simulator) does not necessarily have a bearing on the role of the audience. Whilst Dust and Whist for example, are both interactive, one is a Simulation of Captivity and the other is Up Close and Personal.

\section{Collaborative Partnerships}

In 2002, Scott DeLahunter remarked that choreographers will only be able to fully respond to the potential of VR technologies by working collaboratively with the technology developers, requiring '...more attention to the mechanisms for fostering, funding and facilitation of collaborations that will enable this' (112). This has certainly been reflected in the different types of collaborative part- 
nerships across the works discussed in this paper - independent choreographers collaborating with VR filmmakers, creative technologists collaborating with independent choreographers, established dance companies working with National Museums, VR filmmakers and production houses, VR platforms and VR headset companies. Two types of collaboration seem to have come to the fore collaborations between choreographers and VR filmmakers/production houses, and collaborations that also involve organisations linked the the VR technologies or platforms for VR content.

In his book Virtual Reality, Rheingold reflects how the 'global fun business' might influence the development of a VR society, the two largest groups of users of new ICT technologies in the 1990s would be the global industries of finance and entertainment (288);

The electronic machinations of instantaneous global markets created by webs of electronic transactions, along with the sitcoms, movies, videos... video games and theme parks that constitute the experience industry today, are the largest driving forces behind tomorrow's information technologies $(1991,288)$.

Rheingold predicted the potential of global partnerships between technology developers and media/ entertainment companies - his suggestion of a fantasy partnership between MIT and Nintendo - the Nintendo-Media Lab is not that far away from initiative like Google Labs, bringing together engineers and researchers, described by Google as 'a playground where our more adventurous users can play around with prototypes of some of our wild and crazy ideas and offer feedback directly to the engineers who developed them.' (Google, 2011). Amongst the pieces described earlier, Giselle and Nightfall were both created in partnership with national ballet companies (English National Ballet and the Dutch National Ballet) and larger technology or media companies, ENB working with the production house Factory 42 and the telecommunications company Sky, who had commissioned the piece for Sky's VR app and the Dutch National Ballet working with Samhoud Media and Samsung.

Due to the combination of artistic and technological expertise necessary for the creation of VR, collaborative teams are central to any VR development process. Indeed, the Dutch National 
Ballet's Online Marketing Manager remarks 'We soon found out that you can not do this alone. Working with virtual reality is a profession apart.' (Cultuurmarketing, 2017). In some cases, these collaborations created creative friction, through which innovative work could be developed, as Baldwin reflects on Through You, 'Our differences were the perfect marriage in this collaboration... We wanted to push the scope of VR by breaking the rules in order to start more conversation about possibility...' (Hills-Duty, 2017c). In terms of the larger team, Baldwin reflects, 'it's been a collective effort requiring blind faith, that's had us doing things we've never done.' (Baldwin, 2017). Through such collaboration, new work can emerge that would not have been possible in isolation;

We both come from seemingly opposite worlds - tech and dance - and we wanted to combine these seemingly disparate worlds to create something fresh, that didn't fit in a box and challenged people to question their assumptions about 'what can be done' in VR (in Astle, 2017).

\section{Final Thoughts}

In 2007 Steve Dixon proposed the possibility that '...in the twenty-first century, VR may become as important and revolutionary an art form as cinema was to the twentieth century' (p.394). The six VR dance pieces discussed in this article show the diversity of practice being generated, as artists and technologists work together to articulate and shape the parameters of this emerging art-form. The breath of work discussed here gives a snapshot of the possible future directions of VR dance performance, across different types of virtual environments, different forms of create content, different levels of audience activity and different drivers behind the creation of the work. What unifies these pieces is a desire to innovate and experiment, to push boundaries and create new artistic landscapes and to find new ways to engage audiences with dance practice. What is clear is the vital role that the interdisciplinary teams pays in this emerging practice - the six works would not have been possible with such collaboration in, across and beyond the arts and technology - whether providing creative expertise, technical expertise, the supply of equipment or distribution channels. 
In an earlier wave of VR and Performance development in the 1990s, the Art and Virtual Environments Project was run at the Banff Centre, Canada. Exploring the artistic and performance possibilities of virtual reality, the initiative was regarded as a 'landmark' project (Dixon 2007, 367). Currently, within the UK a similar focus is placed on VR and Performance content creation, across sectors, by Arts Research Councils, Arts Councils and Technology Innovation Centres. CreativeXR for example, is a programme developed by Digital Catapult and Arts Council England, with support from Innovate UK, offering creative practitioners the opportunity to experiment with immersive technologies in order to create 'new experiences that inspire audiences' (CreativeXR, 2017). Focused on the the arts and culture sector, the programme provides creative teams with the opportunity to develop concepts and prototypes of immersive content, including VR. In 201720 teams funds were awarded funding, 4 of which were performance companies. These projects will be completed in 2018. Similarly, in 2017 the Arts and Humanities Research Council, through its Creative Economy Programme, launched it's Research and Partnership Development Call for the Next Generation of Immersive Experiences, stating;

As technology enables experiences to become more immersive we must ensure that UK creative talent can tell its stories, create innovative products and services, and develop startling new experiences within this new medium. We need to preserve our current strengths and to grow the creative and commercial opportunities of the future (AHRC, 2017).

The call was focused on encouraging proposals the explored immersive experiences in areas where the AHRC considered the UK to have world leading creative assets and technology partners, one of which was performance. The call encouraged applicants to consider what kinds of new creative practices could be enabled by immersive technology, what new experiences could be offered to audiences and how this could transform or extend models of performance (AHRC, 2017). Research projects exploring VR content creation across performance areas of music, circus, theatre and dance were awarded funding and these projects will be completed during 2018. 
Hopefully, this current focus on exploring what new creative frameworks can be developed utilising VR technologies and perhaps more importantly, what new creative content can be created for and with these emerging technologies, will enable creative practitioners to explore and articulate the possibilities through collaborative practice rather than being restricted to theoretical possibilities. In 2009 Matthew Causey wrote how the effective use of VR would be dependent on the discovery of VR's performative qualities and he was concerned that VR performance would be a 'mimicry' of the stage (60). I hope that this article has shown the way in which, rather than mimicking traditional staged performance, emerging VR dance performance work has begun to develop new types of practice using the specific affordances of VR technologies, leading to work that whist drawing on the expertise and understanding from traditional live theatre practice, is beginning to develop it's own language.

\section{References}

ACMI. 2017. 'ACMI commission: Stuck in the Middle With You.' ACMI. Accessed 26 March 2018. https://www.acmi.net.au/museum/commissions/acmi-commission-stuck-middle-you/

AHRC. 2017, 'Call Document: AHRC Creative Economy Programme: Research and Partnership Development call for the Next Generation of Immersive Experiences.' AHRC. Accessed 27 March 2018. http://www.ahrc.ac.uk/documents/calls/immersive-call-guidance/

Astle, Randy. 2017. 'Through You: Stopping and Feeling Through Dance and VR.' Filmmaker, August 15. Accessed 26 March 2018. https://filmmakermagazine.com/103102-through-you-stoppingand-feeling-through-dance-and-vr/\#.Wrls_maZNE4

Bakhshi, Hasan, Juan Mateos-Garcia and David Throsby. 2010. Research Briefing: Beyond Live Digital Innovation in the Performing Arts. London: NESTA

Baldwin, Lily (2016) 'Through You - How A New VR Project Dances with Intimacy.' Sundance Institute, Dec 9. Accessed 26 March 2018. https://www.sundance.org/blogs/program-spotlight/ through-you-how-a-new-vr-project-dances-with-intimacy\#/

Baraniuk, Chris. 2016. 'Why we are talking differently about the web.' $B B C$, April 1 . Accessed 26 March 2018. http://www.bbc.com/future/story/20160401-why-were-talking-differently-about-theweb 
Bellman, Sarah. 2017. 'The First Virtual Reality Ballet Springs to Life in Amsterdam.' Creators:Vice, Jan 22. Accessed 26 March 2018. https://creators.vice.com/en_us/article/pgq7by/dutchnational-ballet-virtual-reality-night-fall

Blake, Bill. 2014. Theatre and the Digital. London: Palsgrave.

Boland, Brooke. 2017. 'I Want To Dance Better With VR.' PXVR, March 27. Accessed 26 March 2018. http://www.pxvr.com/i-want-to-dance-better-with-vr/

Boleslavský, Andrej. 2017. 'VR Dust -Trailer'. YouTube, April 7. Accessed 26 March 2018. https:// www.youtube.com/watch?v=uFnzPG4xzVY

Carver, Gavin and Colin Beardon. 2004. New Visions In Performance: The Impact of Digital Technologies. Routledge: London.

Causey, Matthew. 2009. Theatre and Performance in Digital Culture. London: Routledge.

CreativeXR. 2017. CreativeXR. Accessed 27 March 2018. http://creativexr.co.uk/\#about

Cultuurmarketing. 2017. 'Dutch National Ballet innovates with the first virtual reality show.' Cultuurmarketing. Accessed 27 March 2018. https://www.cultuurmarketing.nl/cases/virtual-reality-nationale-ballet-night-fall/\#.WroZ1WaZNE4

Dansmagazine. 2018. 'Night Fall is the world's first Virtual Reality ballet'. Dansmagazine. Accessed 26 March 2018. https://dansmagazine.nl/nieuws/night-fall-is-s-werelds-eerste-virtual-realityballet

deLahunta, Scott. 2002 'Virtual Reality and Performance.' Performing Arts Journal 70: 105-114.

Dixon, Steve. 2007. Digital Performance: A History of New Media in Theater, Dance, Performance Art, and Installation. Massachusetts: MIT Press

Dixon, Steve. 2006. 'A history of virtual reality in performance.' International Journal of Performance Arts and Digital Media 2 (1): 23-54.

Dormehl, Luke. 2016. 'You'll be blown away by the world's first virtual reality ballet experience .', Digital Trends, July 9. Accessed 26 March 2018. https:/www.digitaltrends.com/cool-tech/virtualreality-ballet/

Dutch National Ballet. 2016. 'The Making of Nightfall'. YouTube, August 25. Accessed 26 March 2018. https://www.youtube.com/watch?v=7VhAUKThR1Y

English National Ballet. 2016. 'Introducing our new virtual reality film inspired by Akram Khan's Giselle.' English National Ballet, Sept 29. Accessed 26 March 2018. https://www.ballet.org.uk/ blog-detail/introducing-new-virtual-reality-film-inspired-akram-khans-giselle/

Escoda, Carla. 2017. 'Is Virtual Reality the Future of Dance?' KQED Arts, Oct 16. Accessed 26 March 2018. https://www.kqed.org/arts/13811546/is-virtual-reality-the-future-of-dance 
Fourmi, Esteban, JiaXuan Hon and Aoi Nakamura. 2016. 'Whist: Dance theatre and Virtual Reality.' British Computer Society. Accessed 26 March 2018. https://ewic.bcs.org/content/ConWebDoc/ 56281

Galando, Paul. 2017. 'New Virtual Reality Dance Program at NYU'. Wall Street Journal, Feb 2. Accessed 26 March 2018. https://www.wsj.com/video/new-virtual-reality-dance-program-at-nyu/ 99D0A2A5-0F24-43B4-ACCB-D5CAA2869F9A.html

Giannachi, Gabriella. 2004. Virtual Theatres: An Introduction. London: Routledge.

Google. 2011. 'Google Labs Frequently Asked Questions.' Google. Accessed 27 March 2018. http://www.googlelabs.com/faq

Gordon, Rebecca. 2017. 'Whist and the gamification of theatre.' Creative Review, July 4. Accessed March 26 2018. https://www.creativereview.co.uk/whist-the-gamification-of-theatre/

Hills-Duty, Rebecca. 2017a. 'WHIST Mixed Reality Theatre Experience Comes To London.' VR Focus, June 23. Accessed 26 March 2018. https://www.vrfocus.com/2017/06/whist-mixed-realitytheatre-experience-comes-to-london/

Hills-Duty, Rebecca. 2017b. 'DUST VR Dance Experience Aims to Show We Are All Starstuff.' VR Focus, Apr 5. Accessed 26 March 2018. https://www.vrfocus.com/2017/04/dust-vr-dance-experience-aims-to-show-we-are-all-starstuff/

Hills-Duty, Rebecca. 2017c. 'VR Dance Performance Through You Released On Gear VR.' VR Focus, Aug 1. Accessed 27 March 2018. https://www.vrfocus.com/2017/08/vr-dance-performancethrough-you-released-on-gear-vr/

Holmes, Kevin. 2017. 'Become a Dust Particle in This VR Performance'. Creators:Vice, April 13. Accessed 26 March 2018. https://creators.vice.com/en_us/article/mgyawp/dust-particle-vr-danceperformance-kinect-vVvV

IF. 2016. 'ACMI teams with Sydney Dance Company and Closer Productions on VR work.' IF, Feb 17. Accessed 26 March 2018. https://www.if.com.au/acmi-teams-with-sydney-dance-companyand-closer-productions-on-vr-work/

King, Tom. 2017. 'Whist-Virtual Reality Experience The Festival Theatre Edinburgh Review.' South Side Advertiser, July 21. Accessed March 26 2018. http://www.southsideadvertiser.biz/WhistVirtual-Reality-Experience-Festival-Theatre-Edinburgh.htm

Laurel, Brenda. 1991. Computers as Theatre. Boston: Addison-Wesley.

Lee, Riordan. 2018. 'Explore someone else's dreams in this bold new VR art installation.' Lostateminor, Jan 9. Accessed 26 March 2018. https://www.lostateminor.com/2018/01/09/exploresomeone-elses-dreams-bold-new-vr-art-installation/ 
Little Black Book Editorial. 2017. 'WHIST - The Innovative Freudian VR Play That Challenges the Mind and Body.' Little Black Book. Accessed 26 March 2018. https://lbbonline.com/news/whistthe-innovative-freudian-vr-play-that-challenges-the-mind-and-body/

NSW Government. 2018. 'Interview with Matthew Bate: Stuck in the Middle with You'. NSW Government. Accessed 26 March 2018. http://screen.nsw.gov.au/news/interview-with-matthewbate-stuck-in-the-middle-with-you?enews $=227$

Milk, Chris. 2016. 'The birth of virtual reality as an art form.' TED, Feb. Accessed 27 March 2018. https://www.ted.com/talks/chris_milk_the_birth_of_virtual_reality_as_an_art_form\#t-678832 O’Brien, Róisín. 2017. 'WHIST: An intriguing new step for dance and physical theatre.' Seeing Dance, Aug 1. Accessed 26 March 2018. http://www.seeingdance.com/whist-04082017/

Perkovic, Jana. 2016. 'Audience takes centre stage in pioneering virtual reality dance film'. The Guardian, March 7. Accessed 26 March 2018. https:/www.theguardian.com/stage/2016/mar/07/ audience-takes-centre-stage-in-pioneering-virtual-reality-dance-film

Pangburn, DJ. 2016. 'Experience Digital Love in the VR Dance Project 'Through You'.' Creators:Vice, Dec 12. Accessed 26 March 2018. https://creators.vice.com/en_au/article/yp5yey/experience-digital-love-in-the-vr-dance-project-through-you

Reaney, Mark. 1996. 'Virtual Scenography: The Actor, Audience, Computer Interface.' Theatre Design and Technology 29 (2): 36-43.

Rheingold, Howard. 1991. Virtual Reality: The Revolutionary Technology of Computer-Generated Artificial Worlds - and How It Promises to Transform Society. New York: Touchstone.

Rheingold, Howard. 1994. 'Rheingold's Reality.' Cyberstage 1 (1): 34.

Sachtman, Noah. 2008. '26 years after Gibson, Pentagon defines 'Cyberspace'.' Wired, May 23. Accessed 26 March 2018. https://www.wired.com/2008/05/pentagon-define/

Samhoud Media. 2018. 'Nightfall'. Samhoud Media. Accessed March 26 2018. https:// samhoudmedia.com/distibutions/night-fall

Sedor, Alexandra. 2017. 'Immersive Dance Piece 'DUST' Allows Users to Become Free-Floating Eternal Particles Traveling Through Space.' vrandfun, April 4. Accessed 26 March 2018. https:// www.vrandfun.com/immersive-dance-piece-dust-allows-users-to-become-free-floating-eternalparticles-traveling-through-space/

Sharir, Yacov. 1997. 'Influence of Technology.' http://www.arts.state.tx.us/studios/sharir/techno.htm

Shirky, Clay. 2011. Cognitive Surplus. London: Penguin.

Sky Arts. 2016. 'English National Ballet - Giselle VR | Sky Arts.' Facebook, 2016. Accessed March 26 2018. https://www.facebook.com/SkyArtsHD/videos/10154470724381153/ 
Sydney Dance Company. 2016. 'Stuck In The Middle With You: A Virtual Reality Film.' Sydney Dance Company, Nov 25. Accessed 26 March 2018. https:/Www.sydneydancecompany.com/stuckmiddle-virtual-reality-film/\#.WoL1sVJ0dE4

Tanner, Hayley. 2017. 'WHIST - The innovative Freudian virtual reality play that challenges the mind and body.' Hack \& Craft, Sept 22. Accessed 26 March 2018. http://hncnews.com/whistinnovative-freudian-virtual-reality-play-challenges-mind-body

White, Vanessa. 2016. 'The World's First Ballet Virtual Reality Premiere.' VR Scout, August 31. Accessed March 26 2018. https://vrscout.com/news/ballet-virtual-reality/\# 